\title{
Patriarchal Hierarchy? Gender, Children's Housework Time and Family Structure in Post-Reform China
}

\author{
Yang $\mathrm{Hu}$ \\ Department of Sociology, Lancaster University, UK \\ Email: yang.hu@,lancaster.ac.uk \\ Phone: $+44(0) 1524593429$
}

Address: Department of Sociology, Bowland North, Lancaster University, Lancaster LA1 4YN, UK

\section{Author Biography}

Yang $\mathrm{Hu}$ is a Lecturer in the Department of Sociology at Lancaster University, UK. He obtained his Ph.D in Sociology as a Gates Scholar from the University of Cambridge. His research focuses on the sociology of families and intimate relationships, race/ethnicity and migration, and East Asian societies. His is the author of the book Chinese-British Intermarriage-Disentangling Gender and Ethnicity. His recent research has appeared in the Journal of Marriage and Family, European Sociological Review, Journal of Sex Research, Demographic Research, Environment and Planning A, Journal of Family Issues, and British Journal of Sociology of Education.

\section{Disclaimer}

The data used in this research are from the China Family Panel Studies (CFPS), funded by the 985 Program of Peking University and carried out by the Institute of Social Science Survey at Peking University. The author is solely responsible for the analyses and interpretations presented in this article. 


\begin{abstract}
Drawing on data from the 2010 China Family Panel Studies, this research investigates the gendered patterns of the time spent by girls and boys on housework in families with distinct structures, with the presence at home or absence from home of the mother, father, elder/younger sister and brother, and male/female extended family members. The results support the theory of gendered domestic labor substitution, as children are seen to "substitute" for the lack and benefit from the surplus of domestic labor resulting from the absence/presence of other male and female family members. The results also depict a neopatriarchal hierarchy that regulates the complex (re)production of domestic gender inequalities in the Chinese family. Addressing the intersection between the "stalled" and "uneven" domestic gender revolution and the increasing diversity of family forms in postreform China, this research underlines the importance of mainstreaming children into research on the gendered division of domestic labor.
\end{abstract}

\title{
Key Words
}

Children, China, Family Structure, Gender, Housework Time, Patriarchal Hierarchy 


\section{INTRODUCTION}

China's "stalled" and "uneven" gender revolution is a tale of two spheres (Ji et al. 2017). In the public sphere, the establishment of a socialist regime, gender-equality legislation and the subsequent Cultural Revolution mobilized masses of women to join the labor market (Ji et al. 2017). In the socialist era, more than 90 percent of Chinese women were part of the labor force (Organisation for Economic Co-operation and Development (OECD) 2015; Wu and Zhou 2015). Although this rate dropped somewhat in the post-reform era, when the Chinese government relaxed its reinforcement of socialist ideals, women's labor force participation rate has remained high, at around 72 percent in the 1990s and 64 percent in the early 2010s (OECD 2015; Wu and Zhou 2015). However, a sharp contrast is found in the domestic sphere, where the gendered division of unpaid domestic labor persists and women continue to shoulder the lion's share of housework (Yu and Xie 2011; Zhang 2017). Previous research indicates that women spend 19.5 and 15.2 hours per week on housework in rural and urban China respectively - three times as much as that of their male counterparts (Yu and Xie 2011).

Although previous research has addressed the gendered patterns of adults' and mainly couples' housework activities (Bittman et al. 2003; Hu and Yucel 2017; Killewald 2011; Yu and Xie 2011; Zhang 2017), such patterns do not emerge in adulthood; they can be traced back to gendered socialization during childhood (Goffman 1977; Raley and Bianchi 2006). Previous research has consistently shown that girls spend twice as much time as boys on housework in the United States (Blair 1992; Raley and Bianchi 2006), Sweden (Evertsson 2006), Spain (Álvarez and Miles-Touya 2012) and China (Hu 2015). Whilst children are free from the direct influence of economic specialization (Becker 1991), the gendered pattern of children's housework time calls into question the long-standing assumption that women's participation in paid employment may eventually lead to greater gender equality at home 
(Gupta 2006). Against this backdrop, examination of children's housework participation may provide crucial insights into the (re)production of gender inequalities in domestic settings.

A burgeoning body of literature underlines the importance of familial context to children's gender-role socialization (Goffman 1977; McHale, Crouter, and Whiteman 2003). However, most of this research has focused on so-called "intact" two-parent families (e.g., Álvarez and Miles-Touya 2012; Antill et al. 1996; Cunningham 2001; Evertsson 2006; Hu 2015). Although the two-parent norm is becoming obsolete in many societies (Treas, Scott, and Richards 2014), we know little about how different family structures - the presence or absence of one or both parents, sibling(s) and extended family members - may affect boys' and girls' housework participation. In China, the 2010 Census revealed that the two-parent nuclear model accounts for only 33 percent of all families - a drop from 54 percent in 1990 (Wang 2014). Due to China's phenomenal internal migration, as many as 61 million leftbehind children, i.e., 22 percent of all Chinese children, experience the absence of one or both parents from home ( $\mathrm{Lu} 2012$ ). Due to the increasing diversity of family structures in China, insights drawn from two-parent families may not be sufficient to provide a thorough understanding of the complex ways in which gender-role socialization operates across family structures.

Using data from the 2010 China Family Panel Studies, this research examines the roles played by distinct family structures - namely the presence or absence of specific family members at home - in shaping the housework time of children aged 10-15 years old. It thus contributes to scholarship in at least two ways, as follows.

1. In addressing the paucity of research on the gendered patterns of children's housework time, particularly in a non-Western developing context, the research sheds new light on the early formation of gendered housework behaviors. It places children at the center rather than on the periphery of study to enable critical reflection on existing theories of the gendered 
division of domestic labor formulated based on adulthood and the couple-dyad model (Becker 1991; Bittman et al. 2003; Hu and Yucel 2017; Killewald 2011).

2. The research offers direct insights into demographic changes in China (Logan, Bian, and Bian 1998; Greenhalgh 2008; Tam, Wong, and Wang 2014) and their potential implications for the reproduction of gender (in)equalities. The increasingly diverse structures of the Chinese family provide a unique opportunity to examine how children may relate to old and new demographic conditions — such as extended family co-residence and singleparenthood (Wang 2014) — in a gendered fashion. As the Chinese government continues to privatize domesticity as the responsibility of individual families ( $\mathrm{Ji}$ et al. 2017), it is pertinent to examine the ways in which girls and boys relate to the division, delegation and organization of housework within the family.

\section{THEORETICAL CONSIDERATIONS AND HYPOTHESES}

\section{Gendered Domestic Labor Substitution}

Children's housework participation has to be considered against the backdrop of China's drastic social, cultural and institutional changes in the past few decades. As theorized by Ji et al. (2017), rising gender inequalities, particularly in the domestic sphere, has been driven by the "familialization" of domestic responsibilities in China's socialism-to-market transition. In the socialist era, domesticity was subsumed under the public sphere, as chores such as cooking, childrearing, etc. were collectively organized as part of the danwei system (Zuo and Jiang 2009). In the post-reform era, the collapse of the danwei system and the abolishment of socialist welfare mean the domestic responsibilities originally assumed by state institutions is offloaded onto individual families (Ji et al. 2017). Meanwhile, the decline of Marxist egalitarian ideologies has gone hand in hand with the resurgence of Confucian patriarchy in post-socialist China (Santos and Harrell 2016; Zuo and Jiang 2009). These developments 
provide the moral and ideological justification for Chinese families and particularly females to take over domestic responsibilities (Ji et al. 2017). As an integral part of the family, children create domestic demand and may at the same time share the burden of domesticity (Hofferth and Sandberg 2001). While previous research has mainly focused on the "familialization" of unpaid domestic work for adults, it is important to examine children's housework participation in reproducing domestic gender inequalities in post-reform China.

Family is a "gender depot" (Goffman 1977). Family socialization plays a pivotal role in shaping children's immediate gender performance and long-term gender role orientation. Existing theories specify three complementary and concurrent mechanisms that are responsible for the intergenerational reproduction of domestic gender inequalities. First, behavior-modeling theory indicates that children actively imitate their parents' gendered housework behaviors along the mother-daughter and father-son lines (Hu 2015). Second, gender socialization takes place as adult family members and children participate in joint housework activities along the same-sex lines (Raley and Bianchi 2006). Third, parents and other adult guardians actively distinguish between female and male children and reinforce this distinction by assigning sex-typed housework tasks to children (Blair 1992). However, theories of intergenerational gender-role socialization are generally predicated on the assumption that both parents are present, and address the influence of their relative gender roles on children's housework behavior (Antill et al. 1996; Hu 2015; Lundberg 2005). Therefore, these theories provide insufficient information on whether and how the absence of one or both parents and the presence of other family members may configure children's gendered participation in housework.

Building on the economic model of the family (Becker 1991), theories of household economics conceptualize the division of domestic labor as a zero-sum trade-off between demand and supply (Gershuny and Sullivan 2014). Each household member creates domestic 
demand and at the same time contributes to the supply of domestic labor (Becker 1991; Brines 1993). In an ideal situation of perfect equality, every family member supplies the amount of domestic labor that she/he demands. Nevertheless, due to the prevalence of gender norms that associate masculinity and femininity with paid and unpaid labor, respectively (Becker 1991; Brines 1993), gender roles are specialized: men typically engage in paid labor and are encouraged by both their maneuver of socio-economic resources and their limited time availability to offload their housework responsibilities onto female family members (Bianchi and Milkie 2010; Gupta 2006).

In their theory of gendered domestic labor substitution, new home economists argue that given the unequal demand-supply balance of domestic labor between family members, the presence or absence of a given family member may have gendered effects on the amount of housework performed by other family members (Benin and Edwards 1990; Brines 1993; Coltrane 2000; Lundberg 2005). Woman, who are expected to act as the major housekeepers, typically supply more domestic labor than the demand they create (Bittman et al. 2003). Therefore, the absence of a female from the home may entail an increased demand for housework from other (usually female) family members to substitute for a deficit in domestic-labor provision (Brines 1993). Similarly, as men usually supply less domestic labor than the demand they create, other (female) family members may be required to do more housework to substitute for the deficit in domestic labor created by men's presence at home (Benin and Edwards 1990; Brines 1993; McHale et al. 2003). Alternatively, families may resort to domestic outsourcing to balance the trade-off between domestic-labor demand and supply (Killewald 2011).

The employment status of family members matters. As in many Western countries (Bianchi and Milkie 2010), working women in China generally spend less time on housework than full-time housewives, although a small minority of high-earning women may "perform" 
gender by doing more housework (Yu and Xie 2011). The latter phenomenon, "gender display," is unlikely to significantly differentiate working from non-working women in China, because female labor force participation has been widely normalized under Chinese socialism (Ji et al. 2017; Wu and Zhou 2015). Therefore, non-working women are likely to provide more domestic labor than their working counterparts due to their greater time availability. In contrast, as Chinese men are normatively expected to serve as the economic pillars of their families, non-working men may “do" masculinity by doing less housework than their working counterparts to compensate for their deviance from patriarchal norms (Tam, Wong, and Wang 2014). Thus, the presence of non-working men at home, compared with their working counterparts, may entail a greater deficit in domestic-labor provision.

Theories of gendered domestic labor substitution have been used predominantly to study adults' housework; children remain largely marginalized in the literature on household economics. Based on the assumption that children are "incomplete" social actors who rely on adults for domestic subsistence, the majority of the research in this field has focused onesidedly on how the presence or absence of children may influence parents' gender roles (see Ji et al. [2017] and Raley and Bianchi [2006] for comprehensive reviews). Nevertheless, children are highly sensitive to the configuration of family structure (Gager, Cooney, and Call 1999; McHale et al. 2003), and should thus be conceptualized as an integral part of the equation of domestic-labor supply and demand. Recent time-use research clearly indicates that adolescents make a non-negligible contribution to housework and are responsive to the demand for domestic labor (Gershuny and Sullivan 2014). Therefore, a key objective of this research is to examine the potential operation of the gendered substitution of housework among girls and boys when other family members are present at home or absent from home.

\section{Hierarchy of Domestic-Labor Substitution in the Chinese Family}


New home economics has long been criticized for insufficiently considering the sociocultural embeddedness of the familial institution (Ferber 1995). Although the theory of gendered domestic labor substitution builds a useful link between family structure and domestic labor, it is crucial to consider how the theory may operate in the Chinese context. "Who substitutes for whom" is closely regulated by the power relations between family members (Ferber 1995; Killewald 2011), and such relations are highly contingent on broader social, cultural and political institutions (Hu 2015; Zuo and Jiang 2009). In the traditional Chinese family, power is conferred by a patriarchal hierarchy structured by gender, generation and age $(\mathrm{Hu}$ and Scott 2016; Jaschok and Miers 1994; Santos and Harrell 2016). First, the gender hierarchy obliges women to be the major housekeepers and compensate for men's domestic-labor deficit (Jaschok and Miers 1994). Second, the top-down generational hierarchy means that although parents, and particularly mothers, are expected to be the major housekeepers (Santos and Harrell 2016), parents are likely to offload any excessive surplus housework burden downwards onto their children rather than upwards to their own parents. Third, within the same generation and gender, elder family members usually have more power than younger ones (Hu and Scott 2016). In the patriarchal hierarchy, individuals with less power are more likely to substitute for others than to be substituted for. At the same time, the order of substitution is also contingent on one's (physical) capability to practically perform housework. This means young children and (elderly) family members in poor health may demand rather than provide substitution. In this section, I draw on the above principles to develop theoretically-informed hypotheses regarding the potential susceptibility of girls' and boys' housework time to the presence or absence of specific members in the Chinese family.

Mother. As Chinese mothers usually undertake the lion's share of the housework (Hu 2015), their presence is likely to create a surplus in domestic-labor supply. Conversely, the absence of mothers from home may lead to a deficit in domestic-labor supply, which may 
require substitution from children according to the generational hierarchy (Benin and Edwards 1990; Jaschok and Miers 1994). Meanwhile, the gender hierarchy renders girls more likely than boys to substitute for their mothers' absence from home (Hu 2015). Furthermore, due to time constraints, working mothers may spend less time on housework than their nonworking counterparts (Bianchi and Milkie 2010; Yu and Xie 2011; Zhang 2017). Therefore, we expect the presence of non-working mothers, compared with that of working mothers, to alleviate children's housework burden to a greater degree.

Hypothesis 1: The presence of mothers at home is negatively associated with children's housework time (1A); the association is stronger for non-working than working mothers (1B); and the association is stronger among girls than boys (1C).

Father. Due to Chinese fathers' longstanding lack of contribution to domesticity, their presence usually creates a deficit in domestic-labor supply (Hu 2015; Yu and Xie 2011) that may demand substitution from other family members. Although mothers are usually the primary source of this substitution (Manke et al. 1994), any excessive surplus housework may be offloaded onto children in line with the generational hierarchy, particularly in the absence of the mother. Meanwhile, as the gender hierarchy favors boys over girls (Fong 2002; Hu 2015), girls may be more susceptible to the presence of fathers at home. Moreover, as non-working fathers may do less housework to compensate for their deviance from the normative male-breadwinner role (Yu and Xie 2011), their presence may entail a greater demand for housework substitution than that created by working fathers. 
Hypothesis 2: The presence of fathers at home is positively associated with children's housework time (2A); the association is stronger for non-working fathers than working fathers (2B); and the association is stronger among girls than boys $(2 \mathrm{C})$.

Sibling. Despite the one-child policy, many families in China, particularly in rural areas, have more than one child. As of 2007, according to Greenhalgh (2008), only 37 percent of Chinese families had adhered to the one-child policy. The power relations between siblings are traditionally regulated by a gender-cum-age pecking order (Santos and Harrell 2016). Within this hierarchy, male siblings have more power than female siblings; and within the same gender, elder siblings have more power than younger ones (Jaschok and Miers 1994). These sibling power relations have been shown to operate in multiple contexts, such as family decisions, the distribution of educational resources, inheritance, and ceremonial rituals such as weddings and funerals (Hu and Scott 2016; Santos and Harrell 2016). Meanwhile, the presence of siblings, particularly younger brothers for girls, may embody the endorsement of patrilineal traditions, which could reinforce the patriarchal hierarchy of housework allocation. Nevertheless, because I focus on children aged between 10 to 15 years old in this research, the children's younger siblings may be limited by their physical capability to perform housework. Therefore, the presence of younger siblings may demand substitution and thus increase the children's housework time, in spite of the patriarchal hierarchy. Taking account of both the patriarchal hierarchy of sibship and practical constraints, we expect the following hypotheses to hold.

Hypothesis 3: Girls' housework time is positively associated with the presence of younger sisters, elder sisters, younger brothers and elder brothers, respectively (3A); 
these associations are stronger when elder sisters work (3B) and elder brothers do not work (3C).

Hypothesis 4: Boys' housework time is negatively associated with the presence of elder sisters (4A), and positively associated with that of younger sisters, younger brothers and elder brothers, respectively (4B); these associations are stronger when elder sisters do not work (4C) and elder brothers do not work (4D).

Extended family. The influence of extended family members' presence in the home on children's housework participation has rarely been discussed in existing scholarship. Thus, its incorporation in the current research is exploratory in nature. Two alternative mechanisms may be at play. On the one hand, capitalizing on the patriarchal generational hierarchy, the presence of extended family members, particularly the elderly, may demand an increased input from younger generations. On the other hand, however, extended family members such as (retired) grandparents are often brought into the Chinese nuclear family for the explicit purpose of helping with domestic labor (Goh 2009; Goh and Kuczynski 2010), particularly given the time constraints faced by dual-earner parents. Furthermore, when one or both parents are absent from home, extended family members often step in as surrogate parents (Lu 2012). Therefore, the domestic help provided by extended family members may alleviate the housework burden of parents and children in the nuclear family (Goh 2009; Goh and Kuczynski 2010). Therefore, if the patriarchal gender-cum-generation hierarchy holds sway, we would expect the presence of female and particularly male extended family members to demand domestic labor substitution from children (Hypothesis 5). However, if the latter conjecture holds true that extended family members are brought into the nuclear family to help with domesticity, we would expect Hypothesis 6 to hold. Further to Hypothesis 5 and 
Hypothesis 6, I also explore whether the work status of extended family members affects the relationship between their presence and children's housework time.

Hypothesis 5: The presence of extended family members is positively associated with children's housework time (5A); the association is stronger for male than female extended families (5B).

Hypothesis 6: The presence of extended family members is negatively associated with children's housework time (6A); the association is stronger for male than female extended families (6B).

\section{DATA AND METHOD}

\section{Data and Sample}

I used data from the child, adult and family panels of the 2010 baseline wave of the China Family Panel Studies (CFPS; see Xie and Hu [2014] for more information). Executed by the Institute of Social Science Survey at Peking University, the CFPS was conducted in collaboration with the Population Studies Center at the University of Michigan. Multi-stage probability-proportional-to-size sampling was used to construct samples weighted in proportion to population structures at the administrative levels of county (or equivalent), village and household. The CFPS surveyed 16,000 households from 25 provinces, with a response rate of 81.28 percent at the household level.

The CFPS 2010 data are suited for the current study for two major reasons. First, individual face-to-face interviews were conducted with both child and adult members of the sampled households, thereby capturing the structural composition of each household. Second, the survey is representative of households from the eastern coast to the western hinterland, and thus captures considerable geographical variations across China. 
The CFPS collected time-use data only from children aged 10-15. To construct the analytical sample, I first eliminated children outside this age range and 120 children who did not attend school. I then eliminated 174 cases with missing information on key variables (i.e., 15 for time use, 134 for family income, and 25 for family structure measures), yielding a final analytical sample of 3,170 school children, of whom 49.3 percent were female and 37.8 percent were from urban areas. The mean age of the girls was 13.10, and that of the boys was 13.03. T-tests and correlation analysis were conducted, and no systematic bias in the dimensions of age, gender or rural-urban residence was found to result from missing information. See Table 1 for detailed sample characteristics.

\section{Dependent Variable: Children's Weekly Housework Time}

The children interviewed in the CPFS were asked how much time on average they spent on housework on a weekday and a weekend day, respectively, during school terms. Time was measured in tenths of an hour. The definition of housework included chores such as cooking, housekeeping, laundry and grocery shopping, but excluded care provision. I calculated the number of weekly hours spent on housework by each child as the dependent variable.

Although concern over the reliability of children's self-reported time use is inevitable, previous research has indicated that adolescents' self-reported time use is in fact very reliable (e.g., Benin and Edwards 1990; Gager et al. 1999). Issues pertaining to social desirability may have affected the children's responses. However, such issues are unlikely to have affected the results: reliable analysis with consistent estimators was still possible, as time use was the dependent variable in the regression analysis and the data obtained from the female and male children were analyzed separately (Wooldridge 2010). In the absence of nationally representative time-diary data, the CFPS provides a usefully fine-grained measurement of people's time use in China. 


\section{Key Predictors: Family Structure}

The key predictors were a series of dummy variables capturing the physical presence at home of given family members - mother, father, younger sister, elder sister, younger brother, elder brother, and female and male extended family members - on a long-term basis (e.g., migration for work, study, etc.). Family members' short-term absence (e.g., tourism) was discounted. In the theory of domestic-labor substitution, the operative concept is the physical presence or absence of a family member, rather than their mere existence (McHale et al. 2003). As it was rare for more than one person to appear in each familial role, I coded as "absent" (0) cases in which a given family role was not physically filled at home and coded as "present" (1) cases in which one or more family members with a given role (e.g., elder sisters) were present at home. Notably, because young babies, toddlers and pre-school children are limited by their physical capability to perform housework, I further distinguished the presence of "pre-school younger sister/brother" (under 7 years old) and "school-age younger sister/brother" (above 7 years old). Due to cell-size considerations, I was not able to adopt a more fine-grained distinction within each sub-group of younger siblings.

I also distinguished the work status of each family member, except for that of the younger sister and brother, who were under the minimum legal working age of 16 years old. Family members were coded as "non-working" if they had spent no time in paid employment or reported having been out of the labor force for more than 12 months. A working family member was defined as an individual who had participated in the labor force or spent time in paid employment in the previous 12 months. Importantly, with its 12-month coverage, the work-status distinction took account of the fact that individuals' short-term unemployment may not indicate their long-term economic standing in the family or their gender-role orientation (Hu, 2015). Dummy variables rather than specific combinations of adult and child 
family members were used to capture family structure because the latter approach would have rapidly reduced cell size and ultimately prevented meaningful analysis (Gershuny and Sullivan 2014). Due to cell-size considerations, I did not further disaggregate parents, elder sibling and extended families by age group or further distinguish between distinct types of extended family members.

\section{Covariates}

I took account of a wide range of individual and family characteristics that may influence children's housework time and/or family structure. Children's age may reflect their capability to perform housework as well as the demand of housework they generate (Hofferth and Sandberg 2001). I included children's age as a linear regressor, as preliminary work showed this to be the most parsimonious specification. As the time available for children to spend on housework is constrained in practice by their educational activities, I also calculated the time children spent on academic studies, namely school hours, extracurricular courses and homework, per week. I included a dummy variable for boarding school (zhudu) attendance, because children at boarding school in China usually leave school on Fridays to spend the weekends at home, where they are likely to undertake housework. As high educational achievement among Chinese women is associated with less traditional gender values $\mathrm{CH}$ and Scott 2016), I controlled for children's educational aspirations using a categorical variable that differentiated between "middle school," "high school (including vocational high school [zhigao])" and "higher education."

Previous research has revealed a considerable rural-urban difference in children's housework time (Hu 2015). This difference was controlled for using a dummy variable capturing children's rural or urban residential status. Given China's phenomenal rural-tourban migration and its potential impact on family structure, gender values and children's 
time use (Hu and Scott 2016; Lu 2012), I also controlled for whether a given child was a rural-to-urban migrant with rural hukou (household registration) but residing in an urban area. Family socio-economic status can affect the affordability of domestic outsourcing (Killewald 2011), and patterns of fertility and extended family co-residence differ considerably along the socio-economic gradient in China (Logan et al. 1998). I controlled for the logarithm form of per capita annual household income in 2010. I also took account of parents' highest level of education using a categorical variable distinguishing between "no education," "primary school," "middle school (including vocational middle school [zhongzhuan]," "high school (including vocational high school [zhigao])" and "higher education". Furthermore, families of distinct structures may differ in their (preferred) total amount of housework. The presence of a family member may affect other members' housework time by configuring the total demand of housework, in addition to gendered domestic labor substitution. Therefore, I also controlled for the family's total housework time per week. Notably, because the CFPS only collected time use data from respondents aged 10 years old and above, the total time did not include that of children aged under 10 years old. However, as young children spend relatively less time on housework (Hofferth and Sandberg 2001), the variable should serve as an adequate proxy for the total housework time of the family, though future data collection should ideally account for the time use of children of all ages.

Because poor health may limit one's capability to perform housework, I experimented with controlling for children's and individual family members' health status. Moreover, (elderly) extended family members can either help with housework or else incur additional housework burden especially if they are in poor health. This means it is possible that the health condition of family members may moderate the influence of their presence on children's housework time. However, as the self-reported health measures and their interaction with family structure variables were not significantly associated with children's 
housework time, and their inclusion neither increased the overall model fit nor affected the results for the other variables, they were excluded from the analysis reported in this article. This may not be surprising because the dependent variable used in this research specifically measures time use pertaining to housework, and time spent on looking after (sick) family members is captured by a different variable on care provision in the CFPS. The use of domestic outsourcing was not included as a covariate as only 1.5 percent of families reported having used paid domestic help. Parents' marital status (i.e., married vs. divorced/widowed) was not included because only less than 2 percent of children had experienced parental divorce or deaths, and preliminary checks showed that the variable did not affect the relationship between parents' absence and children's housework time.

\section{Analytical Strategy}

I used two-level hierarchical linear regression models with random intercepts at the family level to account for the hierarchical nature of the CFPS data, as multiple children may be clustered within the same family. Compared with ordinary least squares regression with Huber-White standard errors, the multilevel approach provides more accurate estimates of standard errors (Maas and Hox 2004). Separate models were fitted for girls and boys and subsequently nested to test for potential gender differences in the regression coefficients (StataCorp 2015). To test the hypotheses, Model 1 included all covariates and familystructure dummies, and Model 2 further included family members' work-status distinction. Specifically, in Model 2, distinct slopes were estimated for given "working" and "nonworking" family members; and the lincom function in Stata was then used to compare the slopes to test for any significant interaction effect between the presence of family members and their work status (StataCorp 2015). 
A variance inflation factor (VIF) test was conducted to ensure that no multicollinearity was present between the predictors, and the resulting VIF values were below the threshold of 2.5. The distribution of the dependent variable, although within a range permitting the assumption of normal distribution, was slightly left-skewed. I thus checked the robustness of the results by fitting alternative Tobit and median regression models. The findings are consistent with those reported here. Furthermore, previous research suggests that the patriarchal hierarchy may take different forms in rural and urban China $(\mathrm{Hu}$ 2015; Hu and Scott 2016). Nevertheless, preliminary tests showed no statistically significant interaction between China's rural-urban context and the family structure variables at the 10 percent level (results for additional and robustness tests are available upon request).

\section{RESULTS}

\section{Descriptive Results}

Table 1 presents the descriptive statistics for the disaggregated samples by children's gender. On average, the girls spent 4.66 hours and the boys spent 3.43 hours on housework per week. Despite Lee and Waite's (2005) observation that females tend to accurately estimate their housework time while males offer over-estimations, the results revealed a considerable gender gap in housework time between girls and boys in China, as the girls were seen to spend 1.2 more hours on housework than the boys per week $(t=8.28, p<0.001)$.

\section{[Table 1 about here]}

Approximately 81 percent of the mothers of both girls and boys, i.e., around 61 percent of working mothers and 21 percent of non-working mothers, were present at home. Compared with the mothers, a larger proportion ( 28 percent) of the fathers were absent from home; these figures were similar for boys and girls. Only 7 percent of the fathers were out of 
work, which can be attributed to the cultural expectation that Chinese men will assume the role of male breadwinner (Jaschok and Miers 1994).

The presence of siblings differed considerably according to children's gender. This may be in part be due to the persistence of patrilineal traditions in China, as families may conceive multiple children in the attempt to ensure a male heir (Greenhalgh 2008). Whilst 5 percent of the sampled girls lived with at least one pre-school younger sister and 14 percent with at least one school-age younger sister, only 9 percent of the boys lived with at least one school-age younger sister $\left(\chi^{2}=15.00, p<0.001\right)$. Consistent with patriarchal demographics (Greenhalgh 2008), girls (12 percent) were twice more likely than boys (6 percent) to have at least one pre-school younger brother $\left(\chi^{2}=35.34, p<0.001\right)$ and more than twice more likely to have at least one school-age younger brother (girls: 26 percent, boys: 10 percent; $\chi^{2}=$ $152.17, p<0.001)$ at home. In contrast, boys (23 percent) were more likely than girls (16 percent) to have an elder sister at home $\left(\chi^{2}=22.48, p<0.001\right)$. There was no significant gender difference between boys and girls (12 percent for both) in their likelihood of having an elder brother.

Around 32 percent of the girls and 29 percent of the boys co-resided with at least one female extended family member. Approximately 27 percent of the children, girls and boys alike, lived with at least one male extended family member. A considerable proportion of the extended family members were not in paid employment. On average, the co-residing female and male extended family members aged 63.36 and 63.58 years old respectively. This is unsurprising, as co-residing extended family members are likely to be retired grandparents.

Approximately 23 percent of the children were attending boarding school. Consistent with existing evidence that Chinese girls academically outperform and out-aspire their male counterparts (Fong 2002), girls spent more time on academic activities (47.17 hours) than boys ( 45.25 hours) per week $(t=3.24, p<0.001)$, and were more likely (66 percent) than 
boys (60 per cent) to report higher educational aspirations $\left(\chi^{2}=10.95, p<0.01\right)$. No significant gender difference in family socio-economic status or parents' education was observed.

[Table 2 about here]

Table 2 presents a bivariate correlation matrix of the key variables. The results delineate the complex interconnections between family members' presence at or absence from home. In line with the two-parent family model, the presence of the mother at home was found to be positively associated with the presence of the father at home. The presence at home of both male and female extended family members was negatively associated with the presence of the mother and the father, respectively. This is consistent with previous research that extended family members are often brought into the nuclear family to help with domestic tasks and childcare in the absence of one or both parents (Goh and Kuczynski 2010). Consistent with the patrilineal preference in China for sons (Greenhalgh 2008), girls are unlikely to have both elder and younger brothers, as parents usually stop conceiving children once they have a male heir.

\section{Multivariate Results}

Table 3 presents the results of the two-level random-intercept models predicting the weekly housework time for girls and boys separately.

\section{[Table 3 about here]}

Mother. The results support Hypothesis 1A: that the presence of mothers at home predicts a decrease in girls' $(B=-1.20, p<0.001)$ and boys' $(B=-0.79, p<0.01)$ housework time, respectively. Hypothesis 1B is also supported, as the negative association between mothers' presence and children's housework time was stronger for non-working than working mothers (between-slope difference: $\chi_{\text {girl }}^{2}=12.12, p<0.001 ; \chi_{\text {boy }}^{2}=9.68, p<$ 
0.01). However, Hypothesis $1 \mathrm{C}$ regarding the gender difference between girls and boys goes unsupported, as the between-coefficient difference was not statistically significant at the 10 percent level. This may be because singleton boys of the one-child generation (who accounted for 44.3 percent of all boys in the analytical sample) are the only available source of domestic-labor substitution for their mothers (Fong 2002; Hu 2015).

Father. Partly in line with Hypothesis 2A, fathers' presence was positively associated with girls' $(B=0.10, n s)$ but not boys' $(B=-0.08, n s)$ housework time. However, these associations were not statistically significant at the 10 percent level. The presence of mothers and other adult females, as the major housekeepers, may "buffer" the impact on children of fathers' deficit in domestic labor provision. Hypothesis $2 \mathrm{~B}$ is partly supported, as the presence of non-working fathers predicts a sharper increase in girls' housework time $(B=$ $0.86, p<0.10)$ than that of working fathers $\left(B=-0.03, n s\right.$; between-slope difference: $\chi^{2}=$ 4.75, $p<0.05)$. The results also support Hypothesis $2 \mathrm{C}$, as the positive association between the presence of non-working fathers and children's housework time was stronger among girls than boys (Model 2A vs. 2B: $\chi^{2}=3.13, p<0.10$ ). It seems that non-working fathers' performance of masculinity in the domestic sphere due to their deviance from the malebreadwinner norm may demand more gendered domestic labor substitution from girls than from boys.

Girls' siblings. Hypothesis 3A is supported, as there was a significant positive association between girls' housework time and living with school-age younger sisters $(B=$ $0.60, p<0.05)$, school-age younger brothers $(B=0.69, p<0.01)$, elder sisters $(B=0.47, p<$ $0.10)$ and elder brothers $(B=0.84, p<0.05)$, respectively. Although the patriarchal age hierarchy demands that younger sisters substitute for their elder sisters, younger children may be unable to physically perform housework. The lack of association between girls' housework time and living with pre-school siblings may be because the dependent variable 
measured time spent on routine housework rather than care provision, and dedicated adults (rather than the girls) may be arranged to take care of young babies and toddlers. The results are consistent with Hypothesis 3B, as the positive association between girls' housework time and living with elder sisters was stronger when the elder sisters worked $\left(B_{\text {working }}=1.27, p<\right.$ $\left.0.05 ; B_{\text {non-working }}=0.33, n s\right)$, although the between-slope difference was not statistically significant at the 10 percent level. Hypothesis $3 \mathrm{C}$ is supported, as the positive association between girls' housework time and living with elder brothers was stronger when the elder brothers did not work $\left(B_{\text {working }}=0.71, n s ; B_{\text {non-working }}=0.87, p<0.05\right)$, although the betweenslope difference was not statistically significant at the 10 percent level. This concurs with gender-performance theory: non-working men may "perform" gender by doing less housework when they deviate from the male-breadwinner norm (Yu and Xie 2011).

Boys' siblings. The results are consistent with Hypothesis 4A, in that boys' housework time was negatively associated with the presence of elder sisters at home $(B=-$ $0.26, n s)$, which is in line with the patriarchal gender hierarchy in which male children take precedence over their female siblings. However, the association was not statistically significant at the 10 percent level. The results are also consistent with Hypothesis 4B, as boys' housework time was positively associated with the presence of elder brothers $(B=$ $0.53, p<0.10)$, school-age younger sisters $(B=0.53, n s)$ and school-age younger brothers $(B$ $=0.06, n s)$, respectively. Similar to the case of girls' housework time, there was no statistically significant association between boys' housework time and living with pre-school siblings. The results do not seem to support Hypothesis 4C and 4D, regarding the work-status distinction for elder sisters and elder brothers respectively. Compared with that of girls, boys' housework participation seems less susceptible to the presence of siblings at home.

Extended family. Hypothesis 6 (domestic help from extended family members) is supported instead of Hypothesis 5 (patriarchal hierarchy of housework substitution). 
Specifically, Hypothesis $6 \mathrm{~A}$ is supported, in that living with both female and male extended family members was negatively associated with girls' $\left(B_{\text {female-extended }}=-0.78, p<0.01 ; B_{\text {male- }}\right.$ extended $=-0.43, n s)$ and boys' $\left(B_{\text {female-extended }}=-0.65, p<0.05 ; B_{\text {male-extended }}=-0.47, p<0.10\right)$ housework time respectively. The results do not support Hypothesis 6B, as the difference between living with female and male extended family members was not statistically at the 10 percent level. Therefore, it seems that female and male extended family members may similarly provide domestic help to the nuclear family. In my further exploration, work-status distinction was not found to moderate (at the 10 percent level) the association between children's housework time and living with extended family members.

Revisiting Table 3 also reveals the important role played by the covariates in configuring girls' and boys' housework time in China. The housework time reported by both girls and boys increased with age. Children's housework participation was shaped by practical constraints. Boarding-school attendance and time spent on academic activities were both negatively associated with children's housework time. Rural girls and boys spent more time on housework than their urban counterparts. Rural-to-urban migrant girls, but not boys, spent more time on housework than non-migrant children. Parents' level of education was negatively associated with children's housework time. Children's agency matters: girls, but not boys, with higher educational aspirations spent considerably less time on housework than girls with lower educational aspirations.

\section{Conclusions and Discussion}

This research brings together two strands of social development in post-reform China: the "stalled" and "uneven" gender revolution in the domestic sphere on the one hand, and the increasing diversity of family forms on the other (Wang 2014). While the former motivates investigation of the gendered patterns of children's housework participation to understand the 
(re)production of domestic gender inequalities from its source, the latter underlines the necessity of situating this investigation relative to distinct family structures to accommodate the potential influence of demographic changes on gendered domestic organization. Drawing on the theory of gendered domestic labor substitution (e.g., Becker 1991; Benin and Edwards 1990; Coltrane 2000; Lundberg 2005), this research analyzed data from the 2010 CFPS and examined the association between girls' and boys' housework time and the presence at home or absence from home of a wide array of family members.

The findings highlight the importance of mainstreaming children into research on the gendered division of domestic labor. Adolescents make a not-insignificant contribution to housework (Gershuny and Sullivan 2014). However, existing research has focused mainly on the ways in which children's presence may exacerbate gender inequalities between parents in terms of paid (e.g., motherhood penalty, fatherhood premium) and unpaid work (see Ji et al. [2017] for a comprehensive review). This research cautions against conceptualizing children as static objects. Rather, it is vividly demonstrated that children are adaptive agents who may adjust their housework contribution in response to their families' distinct structural conditions.

The findings reflect on existing theories of gender-role socialization. Children learn to "do" gender not just by interacting with family members who are present at home, as suggested by the mechanisms of behavior-modeling, parent-child joint activity and sextyping (e.g., Blair 1992; Cunningham 2017; Hu 2015); the sheer presence vs. absence of a given family member matters. With its focus on two-parent families (e.g., Álvarez and MilesTouya 2012; Antill et al. 1996; Cunningham 2001; Evertsson 2006; Hu 2015), previous research offers insufficient insights into children's gendered housework participation given the increasing diversity of family forms in China. According to new home economists (Brines 1993; Coltrane 2000; Lundberg 2005), there is a zero-sum trade-off between the total 
demand for domestic labor created by all family members and the total amount of labor they supply. This means that a deficit in the supply of labor created by one family member may demand a substitution in the form of labor supply from other family members. The findings support this theory of domestic-labor substitution, as children seem to form an integral part of the configuration of the demand-and-supply equation. Yet above and beyond the economic logic, the findings underline the sociocultural embeddedness of children's domestic-labor substitution and the prevalence of a patriarchal economic logic in post-reform China.

The pecking order of children's domestic-labor substitution is regulated by and thus telling of the power relations between family members. The results confirm the persistence of a neo-patriarchal hierarchy along the lines of gender, generation and age in the Chinese nuclear family (Hu and Scott 2016). As mothers are expected to be the major housekeepers, their absence is associated with a significant increase in girls' and boys' housework time. In contrast, the presence of fathers, especially those who do not work, adds to the burden of girls' housework. Girls' housework time is positively associated with the presence of elder sisters and brothers, while boys' housework time is positively associated with the presence of elder brothers but not elder sisters. Living with school-age younger siblings positively predicts both girls' and boys' housework time. This suggests that the order of housework substitution may be subject to family members' (and particularly young children's) practical capability of performing housework, in addition to patriarchal power relations. Nevertheless, although the traditional Chinese patriarchy was built upon the extended-family model (Jaschok and Miers 1994), the findings of this study indicate that the patriarchal hierarchy of housework organization does not readily extend beyond the nuclear family in the post-reform era. The presence of both female and male extended family members reduces children's housework time. This is consistent with previous research that extended families and 
particularly grandparents are often brought into the nuclear family to help with domestic duties (Goh 2009; Goh and Kuczynski 2010; Lu 2012).

As the Chinese government adheres closely to the productivist paradigm (Ji et al. 2017), adult family members engage with and disengage from economic activities at the cost of exacerbating gender inequalities for children in the domestic sphere. Mothers' employment constrains the time available for housework, which calls for domestic-labor substitution from children. Non-working fathers may "do" gender by doing less housework, which again calls for domestic-labor substitution from children, particularly girls. In the postreform era, the Chinese government "re-familialized" and privatized unpaid domestic labor, separating it from the socialist productive sector and offloading domestic responsibilities onto individual families. The resilience of the familial institution, including traditional family relations, the dissolution of socialist egalitarian ideologies and the resurgence of Confucian gender values, was relied upon to offset the lack of welfare legislation (Ji et al. 2017). As argued by Ji et al. (2017), the separation between the domestic and productive spheres has been a major driver of gender inequalities in China's neoliberal market transition. While Ji et al. (2017) mainly focused on the implications of the transition for adults, I reveal that the transition represents not only a state-to-family transfer of domestic responsibilities, but also an offloading of (excessive) domestic burden onto (female) children within the family. Adding to the two-sphere separation framework, I draw attention to the potential role played by Chinese children in absorbing the backlash of the socialism-to-market transition, at the cost of reinforcing and reproducing gender inequalities.

Although children do not participate in paid labor (at least) until the minimum legal working age of 16 years old in China, the reproduction of domestic gender inequalities at an early age has immediate and long-term implications for children's future in both the domestic and public spheres. First, the considerable gender inequalities in children's housework time 
may immediately impinge on children's time availability for other activities such as education, social engagement, leisure, etc. (Hofferth and Sandberg 2001). Many of these activities are crucial to the production of greater gender equality both at home and at work. Second, it is widely acknowledged that gender orientations and behaviors formulated in childhood may have a long-lasting influence on people's gender performance and workfamily orientations in adulthood (Bianchi and Milkie 2010; Cunningham 2001; Evertsson 2006).

The limitations of this research challenge researchers to come up with new ways of theorizing, collecting and analyzing evidence of the (re)production of gender inequalities. First, while this research necessarily relies on generic time-use measures, future researchers should collect nationally representative time-diary data on the time use of adults as well as children of all ages in China. Second, childhood represents a highly volatile stage of the life course, during which individuals rapidly develop the physical capability to undertake housework as well as a sense of individual agency. Future research should draw on longitudinal data to examine the full spectrum of life-course dynamics pertaining to children's gendered housework participation. Third, although this research positions children as the focus of investigation, the results underline the highly "linked" lives of family members. As recommended by Gershuny and Sullivan (2014), this encourages future researchers to develop a more holistic approach to examining the division of housework: not only taking a dyadic or an intergenerational perspective but fully acknowledging the tethered lives of all family members. 


\section{References}

Álvarez, B., and D. Miles-Touya. 2012. “Exploring the Relationship between Parents' and Children's Housework Time in Spain.” Review of Economics of the Household 10(2): $299-318$.

Antill, J. K., J. J. Goodnow, G. Russell, and S. Cotton. 1996. "The Influence of Parents and Family Context on Children's Involvement in Household Tasks.” Sex Roles 34(3-4): $215-36$.

Becker, G. S. 1991. A Treatise on the Family. MA: Harvard University Press.

Benin, M.H., and D.A. Edwards. 1990. “Adolescents' Chores: The Difference between Dualand Single-Earner Families.” Journal of Marriage and the Family 52(2): 361-73.

Bianchi, S. M. and M. A. Milkie. 2010. "Work and Family Research in the First Decade of the 21st Century." Journal of Marriage and Family 72(3): 705-725.

Bittman, M., P. England, L. Sayer, N. Folbre, and G. Matheson. 2003. "When Does Gender Trump Money? Bargaining and Time in Household Work." American Journal of Sociology 109(1): 186-214.

Blair, S. L. 1992. “The Sex-Typing of Children's Household Labor: Parental Influence on Daughters' and Sons' Housework." Youth \& Society 24(2): 178-203.

Brines, J. 1993. “The Exchange Value of Housework.” Rationality and Society 5(3): 302340.

Coltrane, S. 2000. "Research on Household Labor: Modeling and Measuring the Social Embeddedness of Routine Family Work.” Journal of Marriage and Family 62(4): 12081233.

Cunningham, M. 2001. "Parental Influences on the Gendered Division of Housework." American Sociological Review 66(2): 184-203.

Evertsson, M. 2006. “The Reproduction of Gender: Housework and Attitudes towards 
Gender Equality in the Home among Swedish Boys and Girls.” The British Journal of Sociology 57(3): 415-436.

Ferber, M. A. 1995. "The Study of Economics: A Feminist Critique." American Economic Review, 85(2), 357-361.

Fong, V. L. 2002. "China's One-Child Policy and the Empowerment of Urban Daughters.” American Anthropologist 104(4): 1098-1109.

Gager, C. T., T. M. Cooney, and K. T. Call. 1999. “The Effects of Family Characteristics and Time Use on Teenagers' Household Labor.” Journal of Marriage \& Family 61(4): 98294.

Gershuny, J., and O. Sullivan. 2014. "Household Structure and Housework: Assessing the Contributions of All Household Members, with a Focus on Children and Youths." Review of Economics of the Household 12(1): 7-27.

Goffman, E. 1977. “The Arrangement between the Sexes." Theory and Society 4(3): 301-31.

Goh, E. C. L. 2009. “Grandparents as Childcare Providers: An In-Depth Analysis of the Case of Xiamen, China.” Journal of Aging Studies 23(1): 60-68.

Goh, E. C. L., and L. Kuczynski. 2010. “'Only Children’ and Their Coalition of Parents: Considering Grandparents and Parents as Joint Caregivers in Urban Xiamen, China.” Asian Journal of Social Psychology 13(4): 221-31.

Greenhalgh, S. 2008. Just One Child: Science and Policy in Deng's China. CA: University of California Press.

Gupta, S. 2006. “Her Money, Her Time: Women's Earnings and Their Housework Hours.” Social Science Research 35(4): 975-999.

Hofferth, S. L. and Sandberg, J. F. 2001. "How American Children Spend Their Time." Journal of Marriange and Family 63(2): 295-308.

Hu, Y. 2015. “Gender and Children's Housework Time in China: Examining Behavior 
Modeling in Context." Journal of Marriage and Family 77(5): 1126-1143.

Hu, Y., and J. L. Scott. 2016. "Family and Gender Values in China: Generational,

Geographic, and Gender Differences.” Journal of Family Issues 37(9): 1267-93.

Hu, Y., and D. Yucel. 2017. "What Fairness? Gendered Division of Housework and Family Life Satisfaction across 30 Countries.” European Sociological Review. Online first: https://doi.org/10.1093/esr/jcx085

Jaschok, M., and S. Miers. 1994. Women and Chinese Patriarchy : Submission, Servitude, and Escape. Hong Kong: Hong Kong University Press.

Ji, Y., X. Wu, S. Sun, and G. He. 2017. "Unequal Care, Unequal Work: Toward a More Comprehensive Understanding of Gender Inequality in Post-Reform Urban China.” Sex Roles 77(11): 765-778.

Killewald, A. 2011. “Opting Out and Buying Out: Wives' Earnings and Housework Time.” Journal of Marriage and Family 73(2): 459-471.

Lee, Y-S., and L. J. Waite. 2005. 'Husbands' and Wives’ Time Spent on Housework: A Comparison of Measures.” Journal of Marriage and Family 67(2): 328-36.

Logan, J. R., F. Bian, and Y. Bian. 1998. "Tradition and Change in the Urban Chinese Family: The Case of Living Arrangements.” Social Forces 76(3): 851-882.

Lu, Y. 2012. "Education of Children Left Behind in Rural China.” Journal of Marriage and Family 74(2): 328-41.

Lundberg, S. 2005. "Sons, Daughters, and Parental Behaviour." Oxford Review of Economic Policy 21(3): 340-56.

Maas, C. J. M., and J. J. Hox. 2004. "Robustness Issues in Multilevel Regression Analysis.” Statistica Neerlandica 58(2): 127-37.

Manke, B., B. L. Seery, A. C. Crouter, and S. M. McHale. 1994. "The Three Corners of Domestic Labor: Mothers', Fathers', and Children's Weekday and Weekend 
Housework." Journal of Marriage and the Family 56(3): 657.

McHale, S. M., A. C. Crouter, and S. D. Whiteman. 2003. “The Family Contexts of Gender

Development in Childhood and Adolescence.” Social Development 12(1): 125-48.

Organisation for Economic Co-operation and Development (OECD). 2015. Employment and Labor Markets: Key Tables from OECD. Paris: Author. doi:10.1787/20752342

Raley, S., and S. Bianchi. 2006. "Sons, Daughters, and Family Processes: Does Gender of Children Matter?” Annual Review of Sociology 401-421.

Santos, G., and S. Harrell. 2016. Transforming Patriarchy: Chinese Families in the TwentyFirst Century. WA: Washington University Press.

StataCorp. 2015. Stata Statistical Software: Release 14. College Station, TX: StataCorp LP.

Tam, S. M., W. C. A. Wong, and D. Wang. 2014. Gender and Family in East Asia. London: Routledge.

Treas, J., J. L. Scott, and M. Richards. 2014. The Wiley-Blackwell Companion to the Sociology of Families. Chichester: Wiley.

Wang, Y. 2014. “An Analysis of Changing Family Structures in Rural and Urban China.” Chinese Social Science 12: 60-77. (Original in Chinese)

Wooldridge, J. M. 2010. Econometric Analysis of Cross Section and Panel Data. MA: MIT Press.

Wu, Y., and D. Zhou. 2015. “Women’s Labor Force Participation in Urban China, 19902010." Chinese Sociological Review 47(4): 314-42.

Xie, Y., and J. Hu. 2014. "An Introduction to the China Family Panel Studies (CFPS)." Chinese Sociological Review 47(1): 3-29.

Yu, J. and Y. Xie. 2011. "The Varying Display of 'Gender Display."” Chinese Sociological Review 44(2): 5-30.

Zhang, Z. 2017. "Division of Housework in Transitional Urban China.” Chinese Sociological 
Review 49(3): 1-29.

Zuo, J. and Jiang, Y. 2009. Urban Women's Work and Family in Social Transition. Beijing: Contemporary China Publishing House (in Chinese). 
Table 1. Sample Characteristics, by Children's Gender

\begin{tabular}{|c|c|c|c|c|c|}
\hline Parameter & Min & $\operatorname{Max}$ & $\begin{array}{c}\text { Daughter } \\
(N=1,565)\end{array}$ & $\begin{array}{c}\text { Son } \\
(N=1,605)\end{array}$ & $\begin{array}{l}\text { Gender } \\
\text { diff. }\end{array}$ \\
\hline Children's weekly housework time (hour) & 0 & 19 & $\begin{array}{c}4.66 \\
(4.34)\end{array}$ & $\begin{array}{c}3.43 \\
(4.00)\end{array}$ & $* * *$ \\
\hline \multicolumn{6}{|l|}{ Parents } \\
\hline Mother & 0 & 1 & 0.82 & 0.81 & $n s$ \\
\hline Working & 0 & 1 & 0.60 & 0.61 & $n s$ \\
\hline Non-working & 0 & 1 & 0.22 & 0.20 & $n s$ \\
\hline Father & 0 & 1 & 0.71 & 0.73 & $n s$ \\
\hline Working & 0 & 1 & 0.64 & 0.66 & $n s$ \\
\hline Non-working & 0 & 1 & 0.07 & 0.07 & $n s$ \\
\hline \multicolumn{6}{|l|}{ Sibling } \\
\hline Pre-school younger sister & 0 & 1 & 0.05 & 0.06 & $n s$ \\
\hline School-age younger sister & 0 & 1 & 0.14 & 0.09 & $* * *$ \\
\hline Pre-school younger brother & 0 & 1 & 0.12 & 0.06 & $* * *$ \\
\hline School-age younger brother & 0 & 1 & 0.26 & 0.10 & $* * *$ \\
\hline Elder sister & 0 & 1 & 0.16 & 0.23 & $* * *$ \\
\hline Working & 0 & 1 & 0.03 & 0.05 & $* * *$ \\
\hline Non-working & 0 & 1 & 0.13 & 0.17 & $* *$ \\
\hline Elder brother & 0 & 1 & 0.12 & 0.12 & $n s$ \\
\hline Working & 0 & 1 & 0.03 & 0.04 & $n s$ \\
\hline Non-working & 0 & 1 & 0.09 & 0.09 & $n s$ \\
\hline Extended family & & & & & $n s$ \\
\hline Female extended family & 0 & 1 & 0.32 & 0.29 & $n s$ \\
\hline Working & 0 & 1 & 0.14 & 0.15 & $n s$ \\
\hline Non-working & 0 & 1 & 0.21 & 0.17 & $*$ \\
\hline Male extended family & 0 & 1 & 0.27 & 0.27 & $n s$ \\
\hline Working & 0 & 1 & 0.16 & 0.16 & $n s$ \\
\hline Non-working family & 0 & 1 & 0.12 & 0.12 & $n s$ \\
\hline Covariates & & & & & $n s$ \\
\hline Age & 10 & 16 & 13.10 & 13.03 & $n s$ \\
\hline & & & $(1.76)$ & $(1.72)$ & $n s$ \\
\hline Boarding school & 0 & 1 & 0.24 & 0.23 & $n s$ \\
\hline Weekly study time (hour) & 0 & 83 & $\begin{array}{c}47.17 \\
(17.07)\end{array}$ & $\begin{array}{c}45.25 \\
(16.32)\end{array}$ & $* * *$ \\
\hline Educational aspiration & & & & & $* *$ \\
\hline Middle school & 0 & 1 & 0.11 & 0.14 & \\
\hline High school & 0 & 1 & 0.23 & 0.26 & \\
\hline Higher education & 0 & 1 & 0.66 & 0.60 & \\
\hline Urban residence & 0 & 1 & 0.37 & 0.39 & $n s$ \\
\hline Rural-to-urban migrant & 0 & 1 & 0.18 & 0.20 & $n s$ \\
\hline Log (family income per capita) & 2 & 12 & $\begin{array}{c}8.38 \\
(0.95)\end{array}$ & $\begin{array}{c}8.47 \\
(0.94)\end{array}$ & $* *$ \\
\hline Parents' education & & & & & $n s$ \\
\hline No education & 0 & 1 & 0.16 & 0.16 & \\
\hline Primary school & 0 & 1 & 0.24 & 0.21 & \\
\hline Middle school & 0 & 1 & 0.34 & 0.36 & \\
\hline High school & 0 & 1 & 0.17 & 0.18 & \\
\hline Higher education & 0 & 1 & 0.09 & 0.08 & \\
\hline Family weekly total housework time (hour) ${ }^{\mathrm{a}}$ & 0 & 100 & $\begin{array}{c}31.64 \\
(20.45)\end{array}$ & $\begin{array}{c}31.64 \\
(19.93)\end{array}$ & $n s$ \\
\hline
\end{tabular}

Note: ${ }^{\text {a }}$ Top 1 percent replaced to be equal to $99^{\text {th }}$ percentile to minimize the influence of outlier cases. Mean score reported for continuous variables, and percentage reported for categorical variables. Standard deviation reported in parenthesis. Dummy variable indicated by a minimum of 0 and a maximum of 1 . For gender-difference tests, two-tailed t-test was conducted for continuous variables and chi-square test was conducted for categorical variables. The percentages of working and non-working family members may not add up to the total percentage of a given category of family member, because multiple members (e.g., multiple elder sisters) may be present in each category in a small number of cases.

$n s=$ not statistically significant at the 10 percent level, ${ }^{*} p<0.05, * * p<0.01, * * * p<0.001$. 
Table 2. Correlation Matrix of Key Variables, by Children's Gender

\begin{tabular}{|c|c|c|c|c|c|c|c|c|c|c|}
\hline & $(1)$ & $(2)$ & (3) & (4) & $(5)$ & $(6)$ & $(7)$ & $(8)$ & $(9)$ & $(10)$ \\
\hline \multicolumn{11}{|l|}{ Girls $(N=1,565)$} \\
\hline (1) Weekly housework time & 1.00 & & & & & & & & & \\
\hline (2) Mother & $-0.10 *$ & 1.00 & & & & & & & & \\
\hline (3) Father & -0.01 & $0.37 *$ & 1.00 & & & & & & & \\
\hline (4) Pre-school younger sister & -0.03 & 0.05 & 0.00 & 1.00 & & & & & & \\
\hline (5) School-age younger sister & $0.12 *$ & 0.01 & 0.04 & -0.02 & 1.00 & & & & & \\
\hline (6) Pre-school younger brother & -0.02 & 0.01 & -0.01 & $0.11 *$ & $0.08 *$ & 1.00 & & & & \\
\hline (7) School-age younger sister & $0.14 *$ & 0.01 & -0.00 & $-0.09^{*}$ & $0.11 *$ & $-0.17^{*}$ & 1.00 & & & \\
\hline (8) Elder sister & $0.09 *$ & 0.03 & 0.04 & $-0.07 *$ & -0.01 & $-0.07 *$ & 0.06 & 1.00 & & \\
\hline (9) Elder brother & $0.10^{*}$ & 0.01 & 0.05 & $-0.08 *$ & $-0.08 *$ & $-0.12 *$ & $-0.17^{*}$ & -0.02 & 1.00 & \\
\hline (10) Female extended family & -0.00 & $-0.36^{*}$ & $-0.18^{*}$ & 0.04 & 0.00 & 0.04 & 0.01 & -0.05 & -0.02 & 1.00 \\
\hline (11) Male extended family & 0.00 & $-0.38 *$ & $-0.22 *$ & 0.06 & -0.03 & 0.04 & 0.03 & -0.06 & -0.03 & $0.63 *$ \\
\hline \multicolumn{11}{|l|}{$\overline{\text { Boys }(N=1,605)}$} \\
\hline (1) Weekly housework time & 1.00 & & & & & & & & & \\
\hline (2) Mother & -0.06 & 1.00 & & & & & & & & \\
\hline (3) Father & -0.02 & $0.34 *$ & 1.00 & & & & & & & \\
\hline (4) Pre-school younger sister & -0.03 & 0.04 & -0.03 & 1.00 & & & & & & \\
\hline (5) School-age younger sister & $0.10^{*}$ & -0.02 & -0.05 & -0.06 & 1.00 & & & & & \\
\hline (6) Pre-school younger brother & -0.02 & -0.01 & -0.01 & -0.01 & -0.01 & 1.00 & & & & \\
\hline (7) School-age younger sister & 0.04 & -0.02 & -0.03 & 0.00 & -0.00 & -0.05 & 1.00 & & & \\
\hline (8) Elder sister & 0.02 & 0.01 & 0.02 & $-0.12 *$ & $-0.07 *$ & $-0.11^{*}$ & $-0.09 *$ & 1.00 & & \\
\hline (9) Elder brother & $0.09 *$ & -0.04 & 0.02 & -0.05 & -0.00 & $-0.08 *$ & -0.04 & 0.04 & 1.00 & \\
\hline (10) Female extended family & -0.00 & $-0.34 *$ & $-0.24 *$ & 0.06 & 0.06 & 0.06 & 0.04 & $-0.09 *$ & -0.01 & 1.00 \\
\hline (11) Male extended family & -0.00 & $-0.32 *$ & $-0.23 *$ & $0.07 *$ & 0.01 & 0.03 & 0.05 & $-0.08^{*}$ & 0.01 & $0.59 *$ \\
\hline
\end{tabular}

Note: Bivariate Pearson's correlation.

$* p<0.01$ 
Table 3. Two-Level Random-Intercept Models Predicting Children's Weekly Housework Time, by Children's Gender

\begin{tabular}{|c|c|c|c|c|c|c|c|c|c|c|c|}
\hline \multirow[b]{3}{*}{ Parameter } & \multicolumn{4}{|c|}{ Girls $(N=1,565)$} & \multicolumn{6}{|c|}{ Boys $(N=1,605)$} & \multirow{3}{*}{$\begin{array}{l}\text { Gend } \\
\text { er } \\
\text { diff. }\end{array}$} \\
\hline & \multicolumn{2}{|c|}{ Model 1A } & \multicolumn{2}{|c|}{ Model 2A } & \multirow{2}{*}{$\begin{array}{l}\text { Work- } \\
\text { status } \\
\text { diff. }^{\text {a }}\end{array}$} & \multicolumn{2}{|c|}{ Model 1B } & \multicolumn{2}{|c|}{ Model 2B } & \multirow{2}{*}{$\begin{array}{l}\text { Work- } \\
\text { status } \\
\text { diff. }^{\text {a }}\end{array}$} & \\
\hline & Coef. & (S.E.) & Coef. & (S.E.) & & Coef. & (S.E.) & Coef. & (S.E.) & & \\
\hline \multicolumn{12}{|l|}{ Parents } \\
\hline Mother & \multirow{3}{*}{\multicolumn{2}{|c|}{$-1.20 * * *(0.32)$}} & & & & $-0.79 * *$ & $(0.29)$ & & & & $n s$ \\
\hline Working & & & $-0.98 * *$ & $(0.32)$ & $* * *$ & & & $-0.68 *$ & $(0.29)$ & $* *$ & $n s$ \\
\hline Non-working & & & $-1.89 * * *$ & $(0.38)$ & & & & $-1.49 * * *$ & $*(0.35)$ & & $n s$ \\
\hline Father & 0.10 & $(0.25)$ & & & & -0.08 & $(0.24)$ & & & & $n s$ \\
\hline Working & & & -0.03 & $(0.25)$ & $*$ & & & -0.13 & $(0.25)$ & $n s$ & $n s$ \\
\hline Non-working & & & $0.86 \dagger$ & $(0.44)$ & & & & -0.38 & $(0.42)$ & & $\dagger$ \\
\hline \multicolumn{12}{|l|}{ Sibling } \\
\hline Pre-school younger sister & -0.20 & $(0.46)$ & -0.03 & $(0.46)$ & & -0.31 & $(0.42)$ & -0.17 & $(0.42)$ & & $n s$ \\
\hline School-age younger sister & $0.60 *$ & $(0.30)$ & $0.66^{*}$ & $(0.30)$ & & 0.53 & $(0.34)$ & 0.47 & $(0.34)$ & & $n s$ \\
\hline Pre-school younger brother & -0.08 & $(0.33)$ & 0.03 & $(0.33)$ & & -0.51 & $(0.41)$ & -0.38 & $(0.40)$ & & $n s$ \\
\hline School-age younger brother & $0.69 * *$ & $(0.25)$ & $0.72 * *$ & $(0.25)$ & & 0.06 & $(0.32)$ & 0.06 & $(0.32)$ & & $\dagger$ \\
\hline Elder sister & $0.47 \dagger$ & $(0.28)$ & & & & -0.26 & $(0.25)$ & & & & $*$ \\
\hline Working & & & $1.27 *$ & $(0.63)$ & $n s$ & & & -0.16 & $(0.45)$ & $n s$ & $*$ \\
\hline Non-working & & & 0.33 & $(0.30)$ & & & & -0.19 & $(0.27)$ & & $n s$ \\
\hline Elder brother & $0.84 *$ & $(0.33)$ & & & & $0.53 \dagger$ & $(0.29)$ & & & & $n s$ \\
\hline Working & & & 0.71 & $(0.61)$ & $n s$ & & & 0.67 & $(0.52)$ & $n s$ & $n s$ \\
\hline Non-working & & & $0.87 *$ & $(0.37)$ & & & & $0.56 \dagger$ & $(0.34)$ & & $n s$ \\
\hline \multicolumn{12}{|l|}{ Extended family } \\
\hline Female extended family & $-0.78 * *$ & $(0.30)$ & & & & $-0.65^{*}$ & $(0.28)$ & & & & $n s$ \\
\hline Working & & & $-0.73 \dagger$ & $(0.38)$ & $n s$ & & & $-0.98 * *$ & $(0.35)$ & $n s$ & $n s$ \\
\hline Non-working & & & $-0.74 *$ & $(0.31)$ & & & & $-0.61 *$ & $(0.30)$ & & $n s$ \\
\hline Male extended family & -0.43 & $(0.31)$ & & & & $-0.47 \dagger$ & $(0.29)$ & & & & $n s$ \\
\hline Working & & & -0.30 & $(0.36)$ & $n s$ & & & -0.50 & $(0.34)$ & $n s$ & $n s$ \\
\hline Non-working & & & $-0.63 \dagger$ & $(0.36)$ & & & & -0.30 & $(0.33)$ & & $n s$ \\
\hline \multicolumn{12}{|l|}{ Covariates } \\
\hline Age & $0.17 * *$ & $(0.06)$ & $0.17 * *$ & $(0.06)$ & & $0.34 * *$ & $*(0.06)$ & $0.35 * * *$ & $*(0.06)$ & & $\dagger$ \\
\hline Boarding school (re & $-1.67 * *$ & $*(0.25)$ & $-1.68 * * *$ & $(0.25)$ & & $-1.79 * *$ & $*(0.24)$ & $-1.79 * * *$ & $*(0.24)$ & & $n s$ \\
\hline Weekly study time & $-0.04 * *$ & $*(0.01)$ & $-0.03 * * *$ & $(0.01)$ & & $-0.02 * *$ & $*(0.01)$ & $-0.02 * * *$ & $*(0.01)$ & & $n s$ \\
\hline \multicolumn{12}{|l|}{$\begin{array}{l}\text { Educational aspiration }(\mathrm{ref}= \\
\text { middle school) }\end{array}$} \\
\hline High school & $-0.69 \dagger$ & $(0.37)$ & $-0.67 \dagger$ & $(0.37)$ & & -0.07 & $(0.32)$ & -0.10 & $(0.32)$ & & $n s$ \\
\hline Higher education & $-1.13 * * *$ & $*(0.34)$ & $-1.10 * *$ & $(0.34)$ & & -0.08 & $(0.29)$ & -0.08 & $(0.29)$ & & $*$ \\
\hline Urban residence $(\mathrm{ref}=\mathrm{no})$ & $-0.91 * *$ & $(0.34)$ & $-0.83 *$ & $(0.34)$ & & $-1.01 * *$ & $*(0.30)$ & $-0.85 * *$ & $(0.31)$ & & $n s$ \\
\hline Rural-to-urban migrant (ref = no) & $1.39 * *$ & $*(0.37)$ & $1.40 * * *$ & $(0.37)$ & & 0.37 & $(0.33)$ & 0.28 & $(0.33)$ & & $*$ \\
\hline Log (family income per capita) & $-0.43 * * *$ & $*(0.12)$ & $-0.42 * * *$ & $(0.12)$ & & $-0.25 *$ & $(0.11)$ & $-0.26^{*}$ & $(0.11)$ & & $n s$ \\
\hline \multicolumn{12}{|l|}{$\begin{array}{l}\text { Parents' education }(\text { ref }=\text { no } \\
\text { education) }\end{array}$} \\
\hline Primary school & $-1.10 * *$ & $(0.34)$ & $-1.08 * *$ & $(0.34)$ & & $-0.77 *$ & $(0.32)$ & $-0.76^{*}$ & $(0.32)$ & & $n s$ \\
\hline Middle school & $-1.18 * *$ & $*(0.33)$ & $-1.16^{* * *}$ & $(0.33)$ & & $-0.86^{* *}$ & $(0.31)$ & $-0.86^{* *}$ & $(0.30)$ & & $n s$ \\
\hline High school & $-1.27 * *$ & $(0.39)$ & $-1.18 * *$ & $(0.39)$ & & $-1.29 * *$ & $*(0.36)$ & $-1.27 * * *$ & $*(0.36)$ & & $n s$ \\
\hline Higher education & $-1.56 * *$ & $(0.50)$ & $-1.56 * *$ & $(0.50)$ & & $-1.42 * *$ & $(0.47)$ & $-1.46 * *$ & $(0.48)$ & & $n s$ \\
\hline $\begin{array}{l}\text { Family weekly total housework } \\
\text { time }\end{array}$ & $0.03 * * *$ & $*(0.01)$ & $0.03 * * *$ & $(0.01)$ & & $0.03 * * *$ & $*(0.01)$ & $0.03 * * *$ & $*(0.01)$ & & $n s$ \\
\hline Constant & $7.03 * *$ & $*(0.48)$ & $6.91 * * *$ & $(0.48)$ & & $5.17 * *$ & $*(0.44)$ & $5.16^{* * *}$ & $*(0.44)$ & & \\
\hline Family variance parameter & $4.02 * *$ & $*(1.06)$ & $3.61 * * *$ & $(1.09)$ & & $5.34 * *$ & $*(1.11)$ & $5.13 * * *$ & $*(1.12)$ & & \\
\hline \multicolumn{12}{|l|}{ Model fit indices } \\
\hline LL (covariates only) & $-4,344$ & $(-4,368)$ & & $-4,337$ & & $-4,383$ & $(-4,393)$ & & $-4,376$ & & \\
\hline BIC (covariates only) & 8,880 & $(8,854)$ & & 8,910 & & 8,95 & $8(8,905)$ & & 8,988 & & \\
\hline Pseudo- $r^{2}$ (covariates only) & 0.192 & $(0.167)$ & & 0.201 & & 0.12 & $8(0.112)$ & & 0.137 & & \\
\hline
\end{tabular}

Note $:$ LL $=$ Log-likelihood. BIC $=$ Bayesian-Information-Criterion. ${ }^{\text {a }}$ Two-tailed test for the slope-difference between working and non-working family member. ${ }^{\mathrm{b}}$ Two-tailed test for gender comparison between Model 1 (for all main variables) and Model 2 (for work-status distinction only). All continuous variables centered at the mean level of the subsamples for girls and boys. $n s=$ not statistically significant at the 10 percent level, $\dagger p<0.10, * p<0.05, * * p<0.01, * * * p<0.001$. 